Methods: This multicentre, randomised, double-blind, parallel-group, placebo (PBO)-controlled phase 3 study (NCT02308163) was conducted in Japan, Korea and Taiwan. All patients had RA diagnosed according to 1987 ACR or 2010 ACR/EULAR criteria. Patients with active RA (defined as $\geq 6$ tender and painful joints and $\geq 6$ swollen joints, using 68 and 66 -joint assessment respectively, and CRP $>0.50 \mathrm{mg} / \mathrm{dL}$ ) and inadequate response to DMARDs (administered for $\geq 90$ days) were randomised in a 1:1:1:2 ratio to 52 weeks' treatment with PBO, peficitinib $100 \mathrm{mg} /$ day, peficitinib $150 \mathrm{mg} / \mathrm{day}$ or etanercept $50 \mathrm{mg} /$ week (open-label reference arm). At week 12, patients initially assigned to PBO were switched (under blinded conditions) to either peficitinib $100 \mathrm{mg} /$ day or peficitinib $150 \mathrm{mg} /$ day until end of treatment. Concomitant stable dose of DMARDs was permitted. The primary efficacy variable was ACR20 response rate at week 12/early termination (ET).

Results: In total, 507 patients were randomised and treated: PBO $(\mathrm{n}=101)$, peficitinib $100 \mathrm{mg} /$ day $(\mathrm{n}=104)$, peficitinib $150 \mathrm{mg} /$ day $(\mathrm{n}=102)$ and etanercept $(n=200)$. Regarding efficacy at week $12 / E T$, significant differences were observed with peficitinib $100 \mathrm{mg} / 150 \mathrm{mg}$ vs PBO $(p<0.001)$ in the proportion of patients achieving ACR20, ACR50, ACR70 (150 mg/day dose only) and DAS28-CRP <2.6, and for change from baseline to week 12/ET in DAS28-CRP (Table 1). Week 0-12 safety results were similar between treatment groups and serious adverse events were more common with PBO than other study treatments (Table 2). For the overall study period, the incidence rate of serious infections per 100 patient-years was higher with peficitinib $100 \mathrm{mg} / 150 \mathrm{mg}$ than PBO (Table 2). There were no deaths during the study.

Conclusion: In patients with RA who had an inadequate response to DMARDs, $100 \mathrm{mg} /$ day and $150 \mathrm{mg} /$ day peficitinib doses significantly reduced RA symptoms according to clinical and patient assessment scores. The proportion of patients achieving the primary efficacy variable (ACR20 at week 12/ET) was significantly greater for both peficitinib doses versus PBO. Peficitinib $100 \mathrm{mg} /$ day and $150 \mathrm{mg} /$ day showed acceptable safety and tolerability, with no new safety signals detected compared with other JAK inhibitors.

Acknowledgement: This study was sponsored by Astellas Pharma, Inc. Medical writing support was provided by Rhian Harper Owen of Cello Health MedErgy and funded by Astellas Pharma, Inc.

Disclosure of Interests: Yoshiya Tanaka Grant/research support from: Abbvie, Astellas, Bristol-Myers Squibb, Chugai, Daiichi-Sankyo, Eisai, MitsubishiTanabe, MSD, Ono, Taisho-Toyama, Takeda, Speakers bureau: Abbvie, Asahi-kasei, Astellas, Bristol-Myers Squibb, Chugai, Daiichi-Sankyo, Eli Lilly, Eisai, Glaxo-Smithkline, Janssen, Mitsubishi-Tanabe, Novartis, Pfizer Japan Inc, Sanofi, Takeda, UCB, YL Biologics, Tsutomu Takeuchi Grant/research support from: Astellas Pharma Inc, Chugai Pharmaceutical Co, Ltd., Daiichi Sankyo Co., Ltd., Takeda Pharmaceutical Co., Ltd., AbbVie GK, Asahikasei Pharma Corp., Mitsubishi Tanabe Pharma Co., Pfizer Japan Inc., Eisai Co., Ltd., AYUMI Pharmaceutical Corporation, Nipponkayaku Co. Ltd., Novartis Pharma K.K., Grant/research support from: AbbVie, Asahi Kasei, Astellas, AstraZeneca, AYUMI, Bristol-Myers Squibb, Chugai, Daiichi Sankyo, Eisai, Eli Lilly Japan, Janssen, Mitsubishi Tanabe, Nippon Kayaku, Novartis, Pfizer Japan Inc, Taiho, Taisho Toyama, Takeda, Teijin, Grant/research support from: Astellas Pharma Inc., Bristol Myers Squibb, Chugai Pharmaceutical Co., Ltd., Mitsubishi Tanabe Pharma Co., Pfizer Japan Inc., Santen Pharmaceutical Co., Ltd., Takeda Pharmaceutical Co., Ltd., Teijin Pharma Ltd., AbbVie GK, Asahi Kasei Pharma Corp., Taisho Toyama Pharmaceutical Co., Ltd., SymBio Pharmaceuticals Ltd., Janssen Pharmaceutical K.K., Celltrion Inc., Nipponkayaku Co. Ltd., and UCB Japan, Consultant for: Astra Zeneca K.K., Eli Lilly Japan K.K., Novartis Pharma K.K., Mitsubishi Tanabe Pharma Co., Abbivie GK, Nipponkayaku Co.Ltd, Janssen Pharmaceutical K. K., Astellas Pharma Inc., Taiho Pharmaceutical Co. Ltd., Chugai Pharmaceutical Co. Ltd., Taisho Toyama Pharmaceutical Co. Ltd., GlaxoSmithKline K.K., UCB Japan Co. Ltd., Consultant for: AbbVie, Asahi Kasei, Astellas, AstraZeneca, AYUMI, Bristol-Myers Squibb, Chugai, Daiichi Sankyo, Eisai, Eli Lilly Japan, Janssen, Mitsubishi Tanabe, Nippon Kayaku, Novartis, Pfizer Japan Inc, Taiho, Taisho Toyama, Takeda, Teijin, Consultant for: Astra Zeneca K.K., Eli Lilly Japan K.K., Novartis Pharma K.K., Mitsubishi Tanabe Pharma Co., Asahi Kasei Medical K.K., AbbVie GK, Daiichi Sankyo Co., Ltd., Bristol Myers Squibb, and Nipponkayaku Co. Ltd., Speakers bureau: Astellas Pharma Inc., Bristol Myers Squibb, Chugai Pharmaceutical Co., Ltd., Mitsubishi Tanabe Pharma Co., Pfizer Japan Inc., Santen Pharmaceutical Co., Ltd., Takeda Pharmaceutical Co., Ltd., Teijin Pharma Ltd., AbbVie GK, Asahi Kasei Pharma Corp., Taisho Toyama Pharmaceutical Co., Ltd. SymBio Pharmaceuticals Ltd., Janssen Pharmaceutical K.K., Celltrion Inc. Nipponkayaku Co. Ltd., and UCB Japan, Speakers bureau: AbbVie, Asahi Kasei, Astellas, AstraZeneca, AYUMI, Bristol-Myers Squibb, Chugai, Daiichi Sankyo, Eisai, Eli Lilly Japan, Janssen, Mitsubishi Tanabe, Nippon Kayaku, Novartis, Pfizer Japan Inc, Taiho, Taisho Toyama, Takeda, Teijin, Speakers bureau: AbbVie GK., Bristol-Myers K.K., Chugai Pharmaceutical Co. Ltd., Mitsubishi Tanabe Pharma Co., Pfizer Japan Inc., Astellas Pharma Inc,
Diaichi Sankyo Co. Ltd., Eisai Co. Ltd., Sanofi K.K., Teijin Pharma Ltd., Takeda Pharmaceutical Co. Ltd., Novartis Pharma K.K., Sakae Tanaka Grant/research support from: KYOCERA Corporation and Asahi Kasei Cor poration, Consultant for: Amgen Astellas BioPharma K.K., KYOCERA Corporation, Pfizer and Daiichi Sankyo Co., Ltd., Speakers bureau: Asahi Kase Corporation, Astellas Pharma Inc, Ayumi Pharmaceutical Corporation, Eisai Co., Ltd., Ono Pharmaceutical Co., Ltd., Daiichi Sankyo Co., Ltd, Taisho Toyama Pharmaceutical Co., Ltd., Mitsubishi Tanabe pharma Corporation, Chugai Pharmaceutical Co., Ltd., Teijin Pharma Ltd., Eli Lilly, Hisamitsu Pharmaceutical Co, Inc., Pfizer, Bristol-Myers., Atsushi Kawakami Grant/ research support from: Astellas Pharma, Consultant for: Astellas Pharma Speakers bureau: Astellas Pharma, Manabu Iwasaki: None declared, Yeong Wook Song: None declared, Yi-Hsing Chen Speakers bureau: Astellas Pharma, Mitsuhiro Rokuda Employee of: Astellas Pharma, Inc., Hiroyuk Izutsu Employee of: Astellas Pharma, Inc., Satoshi Ushijima Employee of: Astellas Pharma, Inc., Yuichiro Kaneko Employee of: Astellas Pharma, Inc. Teruaki Shiomi Employee of: Astellas Pharma, Inc., Emi Yamada Employee of: Astellas Pharma, Inc.

DOI: 10.1136/annrheumdis-2019-eular.1448

\section{FRI0135 INTRAVENOUS PEGYLATED LIPOSOMAL PREDNISOLONE SODIUM PHOSPHATE MORE EFFECTIVE THAN INTRAMUSCULAR INJECTION OF METHYLPREDNISOLONE ACETATE IN TREATING RA PATIENTS WHO ARE EXPERIENCING A FLARE: A PHASE III, RANDOMIZED, DOUBLE-BLIND, DOUBLE DUMMY, ACTIVE CONTROLLED, MULTI-CENTER STUDY}

Johannes W.J. Bijlsma ${ }^{1,2}$, Bart Metselaar ${ }^{3}$, Leonie Middelink ${ }^{4}$, Cees Wortel $^{5}$, Reinhard Bos ${ }^{6}$, Jacob M. van Laar ${ }^{1}$, Harald Vonkeman ${ }^{7}$, Rene Westhovens ${ }^{8}$, Siu Long $\mathrm{Yao}^{9}$, Mudgal Kothekar ${ }^{9}$, Atul Raut ${ }^{9} .{ }^{1}$ University Medical Center Utrecht, Utrecht, Netherlands; ${ }^{2}$ University Medical Center Utrecht, Rheumatology and Clinical Immunology, Utrecht, Netherlands; ${ }^{3}$ Enceladus, Utrecht, Netherlands; ${ }^{4}$ Middelinc BV, Utrecht, Netherlands; ${ }^{5}$ Accelovance, Boston, United States of America; ${ }^{6}$ Medisch Centrum Leeuwarden, Leeuwarden, Netherlands; ${ }^{7}$ Medisch Spectrum Twente, Enschede, Netherlands; ${ }^{8}$ Universitair Ziekenhuis Leuven, Leuven, Belgium; ' ${ }^{9}$ SUN Pharma, Mumbai, India

Background: Intravenous pegylated liposomal prednisolone sodium phosphate is developed to deliver liposomal entrapped prednisolone in the bloodstream; the lipid vesicles allow selective accumulation of glucocorticoids in inflamed tissues by locally increased permeability of blood vessel walls, while limiting systemic exposure.

Objectives: To assess efficacy and safety of liposomes with prednisolone in patients with active rheumatoid arthritis (RA) who are experiencing a flare in comparison to a standard of care medication (methylprednisolone injections). Methods: The study enrolled active RA patients ( $\geq 18$ years) who were experiencing a flare of their disease, defined as a recent switch from a period with well documented remission or low disease activity to an active disease phase, as determined by a change in the Disease Activity Score in 28 Joints (DAS28 $\geq 3.2$ ). Patients were randomized 1:1:1 into liposomal prednisolone $75 \mathrm{mg}$, liposomal prednisolone $150 \mathrm{mg}$ and methylpredniso lone $120 \mathrm{mg}$ groups. Treatment was administered on Day 1 and Day 15. Patients treated with liposomal prednisone IV received IM placebo injections; patients treated with methylprednisolone IM received IV placebo infusions. Evaluations were performed weekly for the first 4 weeks, and every second week thereafter. The primary endpoint was EULAR response rate (good and moderate combined) at Day 8. The primary analysis involved two comparisons: 1) liposomal prednisone $150 \mathrm{mg}$ vs. methylprednisolone $120 \mathrm{mg}$, 2) liposomal prednisone $75 \mathrm{mg}$ vs. methylprednisolone $120 \mathrm{mg}$ Safety results (AEs, vital signs, physical examinations, laboratory, ECG) were also evaluated. A total of 172 patients were screened and 150 were randomized to liposomal prednisone $75 \mathrm{mg}(\mathrm{N}=49)$, liposomal prednisone $150 \mathrm{mg} \quad(\mathrm{N}=52)$ and methylprednisolone $120 \mathrm{mg} \quad(\mathrm{N}=49) .144 \quad(96 \%)$ patients completed the study; mean study duration was 82.9 days; adverse events or intercurrent illness were primary reasons for discontinuation. Results: EULAR response rate at Week 1 (Day 8) was $90.0 \%$ for liposo mal prednisone $150 \mathrm{mg}$ and $85.7 \%$ for liposomal prednisone $75 \mathrm{mg}$ vs $66.7 \%$ for methylprednisolone $120 \mathrm{mg}$ treated patients ( $p$-values of 0.007 and 0.018 , resp.). Other secondary endpoints supported the primary endpoint results showing significant or clinically meaningful improvements in other EULAR response evaluations, as well as DAS28, VAS, ACR20/50/ 70, SF-36, HAQ and FACIT-F assessments. Similar numbers of patients reported at least one adverse event $(A E)$ in each treatment group; 42 $(86 \%), 46(89 \%)$ and $39(80 \%)$, resp., for the liposomal prednisone $75 \mathrm{mg}$, liposomal prednisone $150 \mathrm{mg}$ and methylprednisolone $120 \mathrm{mg}$ groups. Most commonly reported AEs were nausea in the liposomal pre dnisone groups and headache in all 3 treatment arms. Approximately $8 \%$ 
of patients in the liposomal prednisone groups reported AEs related to study drug administration, versus $6 \%$ in the methylprednisolone group. Serious adverse events (SAEs) were reported by $4(8.2 \%), 1(1.9 \%)$ and 2 patients (4.1\%) resp for the liposomal prednisone $75 \mathrm{mg}$, liposomal prednisone $150 \mathrm{mg}$ and methylprednisolone $120 \mathrm{mg}$ groups. Five of the 7 SAEs were treatment related; these included 4 events of hypersensitivity in the liposomal prednisone arms and one event of viral upper respiratory tract infection in the methylprednisolone group.

Conclusion: In this phase III trial, liposomal prednisone $75 \mathrm{mg}$ and 150 mg were significantly more effective than $120 \mathrm{mg}$-methylprednisolone in treating patients with a flare of their RA. The overall incidence of AEs was similar across treatment groups, although hypersensitivity appeared to be more common with liposomal prednisone.

Disclosure of Interests: Johannes WJ Bijlsma Grant/research support from: The department of the author who included patients (JWJB) in the U-Act-Early trial received reimbursements from Roche Nederland BV. JWJB reported grants and fees from Roche, AbbVie, Bristol-Myers Squibb, Merck Sharp \& Dohme, Pfizer, and UCB

University Medical Center Utrecht, Utrecht University, Consultant for: SUN Pharma, Speakers bureau: Lilly, Roche, Bart Metselaar Shareholder of: Enceladus, Grant/research support from: SUN Pharma, Leonie Middelink Grant/research support from: SUN Pharma, Cees Wortel Shareholder of: Enceladus, Accelovance, Grant/research support from: SUN Pharma, Consultant for: SUN Pharma, Reinhard Bos Grant/research support from: SUN Pharma, Jacob M. van Laar Grant/research support from: Genentech, Consultant for: F. Hoffmann-La Roche, Harald Vonkeman: None declared, Rene Westhovens Grant/research support from: Bristol-Myers Squibb, Consultant for: Celltrion, Galapagos-Gilead, Siu Long Yao Shareholder of: SUN Pharma, Employee of: SUN Pharma, Mudgal Kothekar Shareholder of: SUN Pharma, Employee of: SUN Pharma, Atul Raut Shareholder of: SUN Pharma, Employee of: SUN Pharma DOI: 10.1136/annrheumdis-2019-eular.4052

\section{FRI0136 THE EFFICACY AND SAFETY OF SIROLIMUS IN PATIENTS WITH ACTIVE RHEUMATOID ARTHRITIS: A RANDOMIZED AND PARALLEL-CONTROLLED CLINICAL TRIAL}

Jia Wang ${ }^{1}$, Sheng-xiao Zhang ${ }^{1}$, Fang Yuan $\mathrm{Hu}^{1}$, Xiao-Juan Zheng ${ }^{1}$, Ting Cheng ${ }^{1}$, $\mathrm{Na}-\mathrm{Na} \mathrm{Yu}^{1}$, Wen-Xian Yang ${ }^{1}$, Chong Gao ${ }^{2}$, Hong-Yan Wen ${ }^{1}$, LI Xiao-Feng ${ }^{1} .{ }^{1}$ The Second Hospital of Shanxi Medical University, Department of Rheumatology, Taiyuan, China; ${ }^{2}$ Brigham and Women's Hospital, Harvard Medical School, Department of Pathology, Boston, United States of America

Background: We have reported previously that the insufficient absolute number or functional defects of regulatory $\mathrm{T}$ cells (Tregs) in patients with rheumatoid arthritis $(R A)^{[1-3]}$, challenging conventional unspecific immunosuppressive therapy. Sirolimus, a mTOR inhibitor, is reported to allow growth of functional Tregs, which would be able to provide new strategy and target for the treatment of $\mathrm{RA}^{[4]}$.

Objectives: To investigate efficacy and safety of sirolimus combined with conventional immunosuppressants for RA treatment.

Methods: In this non-blinded and parallel-group trial, we randomly assigned 62 patients to receive conventional glucocorticoids and immunosuppressants with or without sirolimus at a dosage of $0.5 \mathrm{mg}$ on alternate days for 24 weeks in a 2:1 ratio. The demographic features, clinical manifestations and laboratory indicators including peripheral blood lymphocyte subgroups and $\mathrm{CD}^{+}{ }^{+} \mathrm{T}$ subsets were compared before and after the treatment.
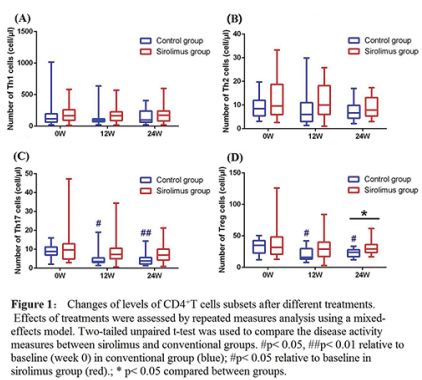

Results: Finally, 37 patients in sirolimus group and 18 in conventional treated group completed 6-month study. By 24 weeks, the patients with sirolimus experienced the significant reduction in disease activity indicators including DAS28, ESR, the number of tender joints and swollen joints $(p<0.001)$. Notably, they had a higher level of Tregs as compared those with conventional therapy alone $(p<0.05)$, indicating that sirolimus could partly restore the reduced Tregs. Concomitantly, their usages of immunosuppressants for controlling disease activity were decreased as compared with conventional group with no difference in blood routine, liver and renal functions both before and after the treatment of sirolimus and between two groups $(p>0.05)$.

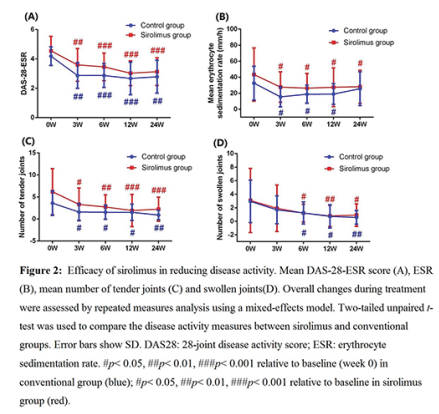

Conclusion: Low-dose sirolimus immunoregulatory therapy selectively up regulated Tregs and partly replaced the usage of immunosuppressants to control disease activity without over-treatment and evaluable side effect. The further study is required using a large sample of RA patients treated with sirolimus for longer period.

\section{REFERENCES :}

[1] Komatsu N, Takayanagi H. Arthritogenic T cells in autoimmune arthritis[J]. The international journal of biochemistry \& cell biology, 2015, 58:92-96. doi:10.1016/j.biocel.2014.11.008.

[2] Morita T, Shima Y, Wing JB, et al. The Proportion of Regulatory T Cells in Patients with Rheumatoid Arthritis: A Meta-Analysis[J]. PloS one, 2016, 11 (9):e0162306.doi:10.1371/journal.pone.0162306.

[3] Spence A, Klementowicz JE, Bluestone JA, et al. Targeting Treg signaling for the treatment of autoimmune diseases[J]. Current opinion in immunology, 2015, 37:11-20.doi:10.1016/j.coi.2015.09.002.

[4] Perl A. Activation of mTOR (mechanistic target of rapamycin) in rheumatic diseases[J]. Nature reviews Rheumatology, 2016, 12(3):169-182. doi:10.1038/nrrheum.2015.172

Acknowledgement: No

Disclosure of Interests: None declared

DOI: 10.1136/annrheumdis-2019-eular.3906

\section{FRI0137 UPADACITINIB IMPROVES PATIENT-REPORTED OUTCOMES IN PATIENTS WITH RHEUMATOID ARTHRITIS AND INADEQUATE RESPONSE TO METHOTREXATE: RESULTS FROM SELECT-COMPARE}

Vibeke Strand ${ }^{1}$, Martin Bergman ${ }^{2}$, Namita Tundia ${ }^{3}$, Andrew Ostor ${ }^{4}$, Patrick Durez ${ }^{5}$, In-Ho Song ${ }^{3}$, Jose Jeffrey Enejosa ${ }^{3}$, Casey Schlacher ${ }^{3}$, Yan Song ${ }^{6}$,

Roy Fleischmann ${ }^{7}{ }^{1}$ Stanford University, Palo Alto, CA, United States of America;

${ }^{2}$ Drexel University College of Medicine, Philadelphia, PA, United States of America ${ }^{3}$ AbbVie Inc., North Chicago, IL, United States of America; ${ }^{4}$ Cabrini Medical Centre, Monash University, Melbourne, Australia; ${ }^{5}$ Université Catholique de Louvain and Cliniques Universitaires Saint-Luc, Brussels, Belgium; ${ }^{6}$ Analysis Group Inc., Boston, MA, United States of America; ${ }^{7}$ University of Texas Southwestern Medical Center, MCRC Center, Dallas, TX, United States of America

Background: Upadacitinib (UPA), a selective JAK1 inhibitor, has demonstrated superior improvement in the clinical signs and symptoms of rheumatoid arthritis (RA) compared with placebo (PBO) and adalimumab (ADA). ${ }^{1}$

Objectives: To evaluate the effect of UPA vs PBO and vs ADA on patient-reported outcomes (PROs) at Week 12 in SELECT-COMPARE (NCT02629159), a randomised controlled trial (RCT) in an active RA population with inadequate responses to methotrexate (MTX).

Methods: Patients in SELECT-COMPARE, a phase 3 RCT, received UPA (15 mg once daily), PBO, or ADA (40 mg every other week) while on background MTX therapy. The following PROs were collected prospectively: Patient Global Assessment of Disease Activity (PtGA) by visual analogue scale (VAS), pain by VAS, Health Assessment Questionnaire Disability Index (HAQ-DI), duration and severity of morning (AM) stiffness, health-related quality of life by Short Form-36 (SF-36), Functional Assessment of Chronic IIIness Therapy-Fatigue (FACIT-F), and Work Instability Scale for RA (RA-WIS). Least squares mean (LSM) changes from baseline $(\mathrm{BL})$ to Week 12 were based on mixed-effects repeated measures 